\title{
Rich Kids of Tehran: The Consumption of Consumption on the Internet in Iran
}

\author{
Ehsan Shahghasemi ${ }^{1}$ (D)
}

Accepted: 17 August 2021 / Published online: 28 September 2021

(C) The Author(s), under exclusive licence to Springer Science+Business Media, LLC, part of Springer Nature 2021

\begin{abstract}
Web 2.0 technologies and social media have given new dimensions to consumerism. Users, overwhelmed with images of prosperous people in wealthy nations, may fantasize about being in their position. In the last decade, new pages on Instagram have emerged with the hashtag \#RichKids. Here, users consume luxurious items and prestigious positions, but vicariously. Borrowing the term "vicarious consumption" from Thorstein Veblen, and slightly modifying it to provide an interpretation of consumers of @ richkidsoftehran (RKOT), the current study argues that this and similar pages not only do little to solve the problems of the followers but also are counterproductive, creating feelings of rage and frustration. It is the consumption of someone else's consumption. Although the human mind can imagine itself in RKOT's position, followers are also aware at all times that this is somebody else's pleasure, not theirs. This study suggests that netizens ought to take a media literacy approach to help themselves understand that their attention is a valuable personal and collective asset, and they should defend it against the forces which seek to take advantage of ordinary people's aspirations.
\end{abstract}

Keywords@ @ richkidsoftehran·RKOT·Thorstein Veblen ·Conspicuous consumption ·Vicarious consumption · Instagram

\section{Introduction: the Paradoxical Rise of Consumerism in Iran}

It is now common for people to follow \#RichKids, a common hashtag on various social media sites around the world. Everyone who has a talent might think of becoming a celebrity, but \#RichKids are people who are famous solely because they are rich. From an austere perspective, it is pathetic and a waste of life to follow what other people consume. However, there are many — particularly in the younger generation — who follow \#RichKids in the hope of sharing in their pleasures. Ours is a world in which consumption per se has become the ultimate goal of life for many people, and since consumption is always hindered by lack of resources, humans have developed subtle ways to consume things they cannot even consume.

In the 1940s, after a study on biographies in popular American magazines, the philosopher and sociologist Leo

Ehsan Shahghasemi

shahghasemi@ut.ac.ir

1 Department of Communication, University of Tehran's Faculty of Social Sciences, Ale-Ahmad Avenue, Tehran, Iran
Löwenthal (who was born in Germany but immigrated to the USA in 1934 and spent the rest of his life there) concluded that the American public's attention and respect had turned from "heroes of production" to "heroes of consumption" (1944, p. 20). The importance of Löwenthal's work was that he had done his study at a time (1942-43) in which the USA was at war with Germany and Japan; hence, people were supposed to be worried more about their very existence than about consumption. Today, Americans have even more opportunities for consumption. The US economy represents $20 \%$ of total global output, the largest output in the world. Moreover, based on an IMF report, the USA has the sixth highest per capita GDP in the world (Focus Economics, 2020). Such a vast economy can provide its citizens an unprecedented horizon of consumption. Each year Americans waste $\$ 165$ billion of food and spend $\$ 100$ billion on shoes, watches, and jewelry. American kids buy $40 \%$ of the world's toys. It is estimated that each house in the USA has three working television sets. And, Americans use 100 billion plastic bags every year (Carey, 2020).

The USA has about $4.3 \%$ of the world's population, but it accounts for almost $50 \%$ of the world's advertising expenditures. Americans are living in a culture saturated with commercial messages. In the 1970 s, every day the average 
American was exposed to about 500 advertisements; by the early 2000s, this number had increased dramatically and reached to 5000 ads per day. One decade later, with the massive adoption of computers and mobile devices, that number had doubled to 10,000 ads per day (Potter, 2019). If Löwenthal lived in our time, he would have many things to say about consumerism and the way it affects our lives. But what would he say about people in those countries that do not enjoy such a fertile watershed for consumption? What would be his judgment about those who live in a country, such as Iran, with a much smaller economy and an official doctrine of seeing consumerism as detrimental to the environment and society and to the spiritual life in this world and our prospects for happiness in the world to come?

The Middle East is not only a geographical place but also an amalgam of cultural, social, economic, linguistic, and racial settings which have been evolving for thousands of years (see, for example, Shahghasemi (2017) and Shahghasemi and Prosser (2019)). Living in the Middle East has its unique hardships and Iran is not an exception. Despite having rich oil fields and reservoirs of natural gas, Iran is considered a poor country. Already having an inefficient economic system mainly based on a state-controlled production system, the country's economy fell into more trouble after Donald Trump announced in 2018 that the USA was going to withdraw the Joint Comprehensive Plan of Action with Iran. Based on a recent report from The World Bank (2020), the recession in Iran exacerbated in 2019/20 as US sanctions were made tighter.

Iran's GDP contracted by $7.6 \%$ in the first nine months of 2019/20 mostly due to setbacks in the oil sector. After Trump withdrew from the Joint Comprehensive Plan of Action, oil production dropped dramatically, reaching a record low of 2 million barrels per day in late 2019 (The World Bank, 2020). A more recent report from The World Bank (2021a, b) notes that continuous international sanctions and the COVID-19 pandemic have tightened pressures on the Iranian economy. Limited access to foreign reserves due to US sanctions culminated in a sharp exchange rate depreciation, which in turn surged prices. Job losses through the pandemic and high inflation worsened welfare, particularly among the poor (The World Bank, 2021a, b). Inflation rose to over $48 \%$ in early 2021. Since April 2020, the Iranian rial has lost half of its value because of US sanctions banning Iran from accessing reserves abroad (The World Bank, 2021a, b). Poverty increased by a percentage point from 2017 to 2018 , reaching $14 \%$ before the pandemic broke out. Before mid-2021, it was estimated that loss in household incomes through the pandemic and the high cost of living, due to inflation, will heighten poverty by 20 percentage points (The World Bank, 2021a, b). And, for the first time in six decades, Iran has requested a $\$ 5$ billion loan from the IMF (Motevali, 2020). Worse than that, the Statistical Center of
Iran has reported that in five years, inequality rose to 39.9 points in 2019 from 38.5 points in 2015 (Sinaiee, 2021).

However, a recent report by Forbes reveals that the number of millionaires in Iran has dramatically increased despite the pressures on this country due to US sanctions and the COVID19 pandemic. There are now 250,000 millionaires in Iran and most of them live in Tehran (Williams, 2021). An ordinary Iranian citizen makes \$150-300 a month, while the monthly salary for an average middle-class individual is about $\$ 400$ 700. Since the living expenses and commodity prices, especially food, have increased, Iranians' income generally no longer covers anything beyond life's necessities. For instance, today, a person who makes $\$ 150$ per month will typically spend two-thirds of it to rent a small one-bedroom apartment (Rahmani, 2021). Based on official statistics, more than $50 \%$ of Iranian are living in "absolute poverty" and the situation is worsening (Entekhab, 2020). As sanctions and inefficiency have damaged the Iranian economy and more Iranian middle-class people lose their socioeconomic status, we are witnessing a growing market of "used" branded commodities (Mostaghim and Etehad, 2019).

\section{Iranians and Consumerism}

Iran is ruled by a theocratic regime based on Shi'ite Islam. Islam takes consumerism as a sin and calls consumerists and those who waste resources "brothers of devils." Hence, Muslims have been discouraged from being consumerists. Verse 141 of the An'am chapter in the Quran reads:

And He it is Who produces gardens (of vine), trellised and untrellised, and palms and seed-produce of which the fruits are of various sorts, and olives and pomegranates, like and unlike; eat of its fruit when it bears fruit, and pay the due of it on the day of its reaping, and do not act extravagantly; surely $\mathrm{He}$ does not love the extravagant.

The founder of the Islamic Republic of Iran, Ayatollah Khomeini, has overtly denounced consumerism and called it a plot by Western countries.

I urge you the young boys and girls not to give away your freedom, human values and independence . . . . for luxury, hedonism and promiscuity; the West and their coward agents inside provide you with depravity centers and as our experiences have shown, they think of nothing but wasting you and distracting you from the destiny of your country, and colonizing you and making you a dependent and consumerist nation (1998, pp. 30-31). 
Current supreme leader of Iran, Ayatollah Khamenei, has also denounced consumerism many times. For example, in 2007 in a public speech in Abarkooh, he said "consumerism ... . [is] our past legacy and unfortunately we have kept this legacy. . . We are too consumerist and we should solve this problem" (quoted in Soori, 2009).

Additionally, for more than a thousand years, many great Iranian poets and writers like Sa'di, Rumi, Saeb Tabrizi, Hafe - and many more - have praised contentment and avoidance of loving material wealth (see, for example, Ebrahimi \& Torabi, 2015).

One might conclude that in a county in which the dominant ideology denounces consumerism and sees this as a sin, and in which economic conditions discourage people from being consumers, the spirit of consumerism should not be as powerful as it is in the West, but such is not the case. Statistics show that Iranian consumerism surpasses in certain regards that of citizens of the wealthiest nations. Tehran is now considered the capital city of the "nose job" (Shahghasemi \& Tafazzoli, 2013) and Iran is one of the leading cosmetic markets in the Middle East and Africa; experts believe Iran will be the fastest growing market for cosmetics during the next eight years (Alliance Experts, 2021). Iranians rank third in the world in energy consumption per capita, and Iran is the fifth buyer of gold in the world (Ranjbar, 2019). Iranians use gasoline 6 times more than the global average (Shafaf, 2015). Iranians are brand lovers; for instance, although Apple Inc. has imposed humiliating sanctions on Iranian users and Iranian Apple users are unable to use many of iPhone capabilities, and the price of an iPhone 12 equals to 8-month income of an Iranian worker, there are still millions of iPhone users in Iran.

On the personal level, one of the most efficient strategies to alleviate poverty is to work, but a growing scholarly literature suggests that more and more Iranians are becoming averse to hard work (see, for example, Raha (2019), Ronen (2011), Nahavandi and Moghadam (2018), among many others). It is therefore not surprising to know that some Iranians do not accept just any job that is available. It is estimated that there are 2.5 million jobs in Iran that nobody wants (Ranjbar, 2014) while there are millions of jobless Iranians desperately looking for a job.

\section{Vicarious Consumption}

I want to focus on what makes Iranians enjoy consuming another person's consumption; this is called vicarious consumption, and it is one of the complexities and wonders of consumerism. The relevance of Löwenthal's work here is that since consumerism is the hallmark of the contemporary life, for Iranians who are grappling with securing their very basic material needs, there is still the tendency to dream of becoming lavish consumers. Aspiring Iranian consumers scramble to keep up with a grandiose life of luxury and consumption. But since the real prospects of being a high-end consumer have become hard, Iranians have found a much cheaper, though bitter, way: vicarious consumption.

\section{Veblen on Consumption}

Thorstein Veblen observed and theorized what he termed "vicarious consumption" in The Theory of the Leisure Class (1899); in this book, he described the evolution of the leisure class and its differentiation from other classes. He dealt with those persons whose occupation was vicarious leisure, who had taken on a new, subsidiary range of duties - the consuming goods that had already been consumed by others, or consuming goods that help them facilitate their masters' consumption. Veblen (1899) states

... there arises a subsidiary or derivative leisure class, whose office is the performance of a vicarious leisure for the behoof of the reputability of the primary or legitimate leisure class. This vicarious leisure class is distinguished from the leisure class proper by a characteristic feature of its habitual mode of life. The leisure of the master class is, at least ostensibly, an indulgence of a proclivity for the avoidance of labour and is presumed to enhance the master's own well-being and fulness of life; but the leisure of the servant class exempt from productive labour is in some sort a performance exacted from them, and is not normally or primarily directed to their own comfort (1899, pp. 41-42).

Veblen's idea of vicarious consumption can well describe our time. But here I want to use a notion of vicarious consumption which is more similar to that of scholars like Ward (2012, p. 4) who wrote, "We have a kind of vicarious share in the lives of our idols." Here, an aspiring consumer is seen as someone who consumes commodities, but through othersmostly through celebrities on social media. Since most aspiring consumers cannot afford to buy extra-expensive commodities and services that celebrities enjoy, a more accessible way is to identify with someone who is conspicuously consuming those services and commodities.

While enjoying a vicarious consumption, one is well aware that this enjoyment is through somebody else's enjoyment. Vicarious consumption is a kind of pleasure in which there is little agency. For most of people, however, there is no option. We have to take the "opium" of vicarious consumption, though we know this relief is only an illusion and soon we have to face the reality. The fact that people simply "trust" the images they see on social media (Sabbar \& Hyun, 2016) and they seem to be unaware that many of 
the pictures shared on social media are carefully crafted to create an illusion of happiness - all this makes their effect even more powerful.

\section{Consuming "Rich Kids of Tehran"}

\#RichKids Instagram pages are important; they offer young Iranian men and women an easy and free way of enjoying consumption. The Instagram page of RichKidsofTehran (RKOT), with about $540 \mathrm{~K}$ followers, reflects the same tenets and stays faithful to the preferred subject of the previous similar pages on Facebook and other SNSs: first-class brat mobiles, massive villas, and pretty young girls in bikinis. This brazen parade of money, flesh, and champagne might seem odd, given that it's coming out of a largely conservative and religious culture - out of a nation that objects to iconography, where alcohol is banned and immodest dressing a crime (Dangerfield, 2015). Following RKOT, other similar pages emerged for rich kids in other Iranian cities like Tabriz, Isfahan, Mashhad, and Shiraz. Because of its transgressive nature, the rhetoric of the spectacle of \#RichKids pages can contribute to a more nuanced perception of the discursive practices surrounding the conceptualization of the wealthy as a distinctive class. The posts published by \#RichKids take advantage of the celebration of wealth and dramatize an almost manic consumption of highly expensive goods and living a high-end life (Spieler, 2015). Let us see how vicarious consumption of RKOT in Iran works.

\section{Depoliticization}

RKOT posts function to depoliticize the society, to distract people from protesting against the status quo, encouraging users to try to find an easy way out of misery and injustice. The foregrounding of consumption and luxury results in a certain depoliticization. Social sciences teach us that the practice, depiction, and critique of conspicuous consumption have political implications. Nevertheless, the emphasis on consumerist lifestyle turns the practices of privilege into a sort of cultural identity that distract us from scrutinizing more pressing issues like socioeconomic inequality in the society. \#RichKids pages do not visualize where the presented luxury items in their posts originate from, or where they really go. In the same manner, politically relevant activities of more sophisticated and politically aware people are likewise eclipsed. Hence, the vision of elite distinction depicted on \#RichKids is relegated into the safely cultural, apolitical, and contextless realm of conspicuous consumption (Spieler, 2015).

There have been some alternative interpretations of the emergence and workings of \#RichKids. Some scholars tend to see these pages as a kind of cultural and even political resistance. However, we should note that in Iran, elites of wealth have always been in close relationship with the political establishment - and one might say that this is true for everywhere else; therefore, one may question simplistic interpretations of RKOT, like that of Partain (2020):

I argue that this group of wealthy Iranian youth has added to worldwide discourse on Iranian culture, expanding lines of communication between the West and Iran. Going beyond assessing the group's impact or worth, I position them as agents in their own mediamaking processes and thoughtful navigators of Iranian and western sociopolitical restrictions. The RKOT both present themselves as and appear racially and ethnically homogenous, not wholly separate from their socioeconomic status and indicative of Iran's history of marginalizing peoples of color (2).

Indeed, RKOT has no such message to the outside world; in fact, a study by Notash et al. (2018) shows that "social literacy" of the RKOT is lower than the society's average. It does not challenge the government, and actively refrains from making political statements or doing anything that upsets the establishment; one cannot help speculating that sooner or later it will be revealed that people who are represented on this page are themselves somehow close to the political elite. The only harm they might do to the power ideology in Iran is that they prove there are pleasures in the Iranian society that should not be there, based on the official values of the Islamic Revolution.

The images are usually juxtapositions of athletic male bodies and signs of wealth: cars, fashion, watches, as well as access to women. Social media offer a safe space for exhibitionism and flaunting for the new Iranian wealthy (Khosravi, 2017). Related to this is the framed semantic reach of the imagery: the total eclipse - the literal invisibility — of other people's position in the socioeconomic hierarchy as well as non-consumption-related dimensions of elite distinction (Spieler, 2015). By showing the present situation in Iran as something that can be defied by the wealthy, RKOT stigmatizes poverty. It successfully convinces most followers that those more than 40 million people who work at two jobs every day just to barely escape being thrown on the streets by the rentiers are poor because they were incapable of using their personal talents; that this is a country in which everyone can become someone and enjoy this lavish life if he or she takes the right path; that if you possess the means to support such an extra-expensive life, you will have the right to be above the laws against self-indulgence and other people have to accept it. This is an incomplete story, not only in Iran, but also in all other countries. A recent report from the Georgetown Center on Education and the Workforce reveals that the likelihood of 
success is too often determined not by a child's innate talent, but by his or her life opportunities - including factors that determine one's opportunities based on class, race, and ethnicity. In short, the system conspires against young people from poor families (Carnevale et al., 2019).

We should not overestimate, however, the extent to which RKOT contributes to the depoliticization and personalization of poverty in Iranian society. There are millions of young Iranians who show a less expensive version of this lifestyle and therefore the role of RKOT in this respect is small. Research has shown that for those who follow the blog for a long period of time, the effects of \#RichKids start to fade. While the initial images might have provoked strong and direct responses - ranging from disgust or envy to appreciation or ridicule - the serialization of the spectacle seriously reduces its affective potential. After the fiftieth Rolls Royce and the two-hundredth bottle of Dom Pérignon, the initial impact is weakened dramatically. After becoming serialized, the spectacle ceases to be spectacular and thus loses its selfcontainment and coherence; the formulaic repetition of spectacular images of elite distinction ultimately renders them rather unspectacular (Spieler, 2015). Perhaps more research is needed to determine how the characteristics of the social media users may correlate to the amount of attention they give to different social media content (Sabbar \& Matheson, 2019) including the content created by RKOT.

\section{The Triumph of the Celebutant(e)s}

By behaving like celebrities and documenting their lives in a virtually similar way, the \#RichKids are able to actually become celebrities, transitioning offline and into the world of actuality. The accumulation of fans and followers on Instagram indicates how convincing these visually chronicled personas are (Gallagher, 2015). Viewed in its entirety, \#RichKids seems to be just a showcase of expensive items. Crucial among them are iconic commodities, ritualized patterns of behavior: holding lavish parties, going on expensive vacations, being seen in high-end venues and fetishized places (interiors and exteriors of mansions). The visual actualization of the variations is characterized by an aesthetics privileging size, exclusivity, and abundance as its dominant formal principles (Spieler, 2015). \#RichKids are people who are famous for being rich, and then, they will become people who are famous for being famous. The pejorative term celebutant (or celebutante) is used as an irony to describe famous people with no manifest quality.

The Persian language is a treasure of hundreds of years of literature and poetry. Almost all sages, poets, and prose writers have admired what Iranians call honar. In Persian, honar is synonymus to "art," but it is an inclusive word that can encompass other concepts like knowledge, poetry, etiquette, and know-how. People who were incapable of having honar used to be denounced, but now we can witness that being without honar or, in more accessible terms, being talentless, has become a privilege in the Iranian celebrity culture. People on RKOT are mainly young men and women whose only talent is being rich.

Theoretically, having no honar can be a source of shame in the Iranian society, but in our increasingly consumerist society, this can function in the other way. Being without quality has made \#RichKids more accessible and more understandable by their "ordinary" followers. Despite their celebrity status, they seem to be "talentless" people like us, and they proudly proclaim their only talent is being rich; therefore, when we cannot enjoy our poor life, we can better enjoy someone's enjoyment who resembles us in their lack of talent. Moreover, the accessibility of social network platforms and sites helps aspiring consumers fall into another illusion. We can revenge celebrities; we cannot be like them, so let us push someone who is like us among them. This new illusion is very effective in helping followers - supposedly - enjoy their vicarious consumption of RKOT. RKOT effectively uses this deceptive strategy, but we can see that employment of this strategy leads people to think they can revenge elite celebrities in other strands of celebrity culture. The popular Iranian talent show of Asre Jadid (meaning "modern times") had TV audiences vote for their favorite contestants, and most of these contestants made sure to construct an image of themselves that was very familiar to mostly poor audience. In a country of 80 million, over 26 million voted. Surely most of them thought they were trying to get one of themselves among the cult of celebrities.

RKOT gives the impression to the followers that they do not need a special talent if they want to enjoy such a high-end life. It's enough to be a conventional businessman or be at the right time at the right place (marry a wealthy man/woman, having life chances of being born in a wealthy family, or winning a big lottery). Therefore, RKOT successfully convinces followers that the lives of those people represented on these pages are not far removed from the lives of the followers who need only to stretch their hands and take their chances. Indeed, resistance to allegedly near and available pleasures is much harder than resistance to far and unreachable pleasures.

\section{Selling Consumerism}

Studying RKOT for the analysis of vicarious consumption in Iran is a good starting point, but we should not end there. Elsewhere (see Shahghasemi, 2020a, b) I have argued that Iranian celebrities on Instagram overtly and covertly encourage people to consume more. Cultural and governmental codes in Iran encourage-and compel-celebrities to reproach consumerism as something harmful to the society; hence, Iranian top celebrities paradoxically preach against consumerism and its wasteful nature, while, at the same time, 
they promote the consumerist lifestyle by showing off their luxury houses, travels, clothing, etc. Moreover, they frequently post promotional content on their pages, and these advertisements are an important source of income. Unlike the people on RKOT, these celebrities overtly attribute their "success" and wealth to their "talent," and therefore, they imply they are worth what they enjoy. In a country of about 80 million, some Iranian celebrities have 10 million followers or more; therefore, it's hard to convince people these celebrities have not the "talent" they claim, and merely know how to exhibit themselves as talented and extraordinary people.

Therefore, in the sense that most celebrities show off their power to consume, they are somehow \#RichKids too; they have developed ways to help followers assume that they are actually participating in the super-expensive consumption the Iranian celebrities enjoy. Many Iranian celebrities claim they have an extraordinary talent, but they had an ordinary life before their talent was discovered. As I mentioned above, this will make them more accessible to the unaware-mainly young - public. Moreover, they sometimes engage with their followers, reply to their comments, or "story" a follower's direct message, to pinpoint their supposed intimacy with their followers. The possibility of live broadcasts also helps Iranian celebrities keep their followers connected to the vicarious consumption option. They imply, "don't stop watching your cellphone, or I might broadcast something live and you will miss it." All these things help followers to better identify with the people who need their attention to stay on top, to be able to make more money, to be able to consume more, and hence, to be able to attract even more attention. This explains why Iranian "heroes of production" are giving way to Iranian "heroes of consumption."

\section{A Pornography of Consumption}

Gail Dines defines pornography as "any product produced for the primary purpose of facilitating male arousal and masturbation" (Dines, 2003, p. 306). Pornography is enjoying the pleasure of someone else; RKOT seems to have nothing to do with pornography, and Instagram applies measures against posting pornographic content. Yet, RKOT's function is technically similar to pornography. RKOT offers the option of enjoying the pleasure of somebody else too.

There are other similarities between pornography and RKOT as well. Both of them concentrate on the visual. They both need to produce spectacular images in order to attract more attention. The image is more important than the content. It is not surprising that some scholars have called the visual depiction of the plight of the African refugees by celebrities as a "pornography of poverty" (see, for example, Shahghasemi, 2020a, b).

Pornography and RKOT both detach events and moments from their immediate and extended environment. They frame scenes and depict everything in an ideal position. Moreover, both of them - as I mentioned above - are apolitical, or depoliticize consumption. Pornography and RKOT are both consumed in seclusion. Most pornographic views happen in private, and rarely do we see people who have gathered together to watch \#RichKids. Keeping viewers and followers detached helps both pornography and RKOT to better show themselves as benign. Pornography and RKOT both fetishize female bodies. Most images on RKOT are either from a male view or show female subjects in a fetishized and passive positions, and this is exactly what porn industry show to its viewership.

\section{The Galling Pleasure of Consuming Consumption}

Not only is Instagram use associated with depression and other bad feelings (see, for example, Donnelly \& Kuss, 2016, Gilchrist, 2017, MacMillan, 2017), but the pleasure of consuming somebody else's consumption is galling. We feel drawn to spectacular posts of \#RichKids; they cater to our sensationalism and address our voyeuristic desires, but we also hate them and turn away in disgust or embarrassment. Spectacle is open to diverse, even contradictory, interpretations and generates strong affective responses (Spieler, 2015). Studying comments under the post of RKOT shows that a considerable number of users are expressing hatred towards those who manage this page or those who are featured in the image posts (see, for example, Falsafi, 2014).

Iranian social media users are notorious for flaming against famous people (see for example Oskuie et al., 2020) and therefore, while more than half a million of them follow RKOT, many of them are enraged at seeing their "stolen pleasures" and post hate comments under each and every post. The same is true for posts of other heroes of consumption. We worship them and we try to virtually participate in their consumption, but as soon as we see them falling, most of us will participate in this mass revenge.

\section{Discussion and Conclusion}

The advent of social media has made the concept of consumption more complicated. But the situation becomes particularly complicated, when in this consumerist time of ours, people of a poor country like Iran want to keep up with the culture of the super-rich. In a bankrupt and poor economy in which equality is worsening, it will become increasingly hard for most Iranians to realize their dream of becoming heroes of consumption. Many young Iranians have found a parallel but insufficient way to vicariously consume goods and services: to consume other people's consumption.

RKOT is the Iranian page on Instagram that facilitates the vicarious consumption of goods and services. The images are carefully chosen and the scenes and props are well 
orchestrated to maximize the effects and help followers better be able to consume what has been consumed by other people. This strategy has been successful in that now more than half a million people are following this page.

Yet, a closer look at this process reveals other details. RKOT followers seem less willing to know that visiting this page will not solve any problem, and even worse, new ones will be created. In order to make changes, one should focus on work, but people spend valuable time following RKOT. Moreover, as a result of the continuous consumption of RKOT, people can become very unsatisfied with their material lives, and this can become one source of daily conflict in families. And, although the RKOT world is only one touch away, people will find this world so remote and untouchable in actuality that they will become frustrated. People realize eventually that their pleasures have been stolen from them and that they are allowed only to vicariously consume goods and services; with RKOT, you are almost there but you will never get there, and you know it. It creates a feeling of frustration that will make young people less likely to believe that the only way to get to one's aspirations is hard work.

The attractions of consumerism on social media will continue to allure people in the years to come, but the detrimental consequences of this phenomenon will force us to develop a kind of media literacy that will defend us from those entities who want to take advantage of it to their own benefit.

Acknowledgements I sincerely thank Daniel Gordon for his thoughtful comments, which helped to improve this paper. I also want to thank Arthur Asa Berger for his inspiring research in the field of luxury.

\section{References}

Alliance Experts (2021). The Iran cosmetics market: Opportunities in the skincare industry. Retrieved June 28, 2021 from https://www. allianceexperts.com/en/knowledge/countries/asia/iran-cosmeticsindustry/.

Carey, J. (2020). 11 stats that will change the way you think about consumerism. Retrieved June 25, 2021 from https://www. relevantmagazine.com/current/11-stats-will-change-way-you-thinkabout-consumerism.

Carnevale, A. P., Fasules, M., Quinn, M., \& Peltier Campbell, K. (2019). Born to Win, Schooled to Lose. Georgetown University Center on Education and the Workforce. Georgetown University Center on Education and the Workforce.

Dangerfield, P. B. (2015). What the Rich Kids of Tehran Instagram Tells Us About Iranian youth culture. Vice, Retrieved July 23, 2020, from https://www.vice.com/en_us/article/yvxdb7/meet-the-rich-kids-oftehran.

Dines, G. (2003). From fantasy to reality: Unmasking the pornography industry. In R. Morgan (Ed.), Sisterhood is forever (pp. 306-314). New York: Washington Square Press.

Donnelly, E., Kuss, D.J. (2016). Depression among users of social networking sites (SNSs): The role of SNS addiction and increased usage. Journal of Addiction and Preventive Medicine, 1 (2), p. 107.
Ebrahimi, E., \& Torabi, Z. (2015). A comparative study of the culture of contentment in the holy Qur'an and in Saadi's Bustan and Gulistan. Journal of literary Quranic Researches, 3(3), 23-47.

Entekhab (2020). Iranian teye 10 sael gozashteh cheghadr faghir shodeand. Retrieved June 28, 2021 from https://bit.ly/3joDH7w

Falsafi, G. (2014). Andar hekayate sabke zendegie bache pooldarhaye Iran. Donyaye Ghalam, 6, 28-29.

Focus Economics (2020). U.S. Economic Outlook. Retrieved June 25, 2021 from https://www.focus-economics.com/countries/unitedstates.

Gallagher, M. M. (2015). John Berger, Paris Hilton, and The Rich Kids of Instagram: The social and economic inequality of image sharing and production of power through self-promotion (2015). Scripps Senior Theses. Paper 545. http://scholarship.claremont.edu/scripps_theses/ 545

Gilchrist, K. (2017). Instagram most likely to cause young people to feel depressed and lonely out of major social apps, study says. Retrieved July 16, 2021 from https://cnb.cx/3kogLWs

Khomeini, R. (1998). Vasiyatnameye mouzoueie emam Khomeini. Tehran: Moassesseye Tanzim va Nashre Asare Emam Khomeini.

Khosravi, S. (2017). The precarious status of working-class men in Iran. Current History, 116(794): 355-359.

Lowenthal, L. (1944). Biographies in popular magazines. In P. F. Lazarsfeld \& F. Stanton (Eds.), Radio Research, 1942-43 (pp. 507-548). New York: Duell, Sloan, and Pearce.

MacMillan, A. (2017). Why Instagram is the worst social media for mental health. Retrieved July 16, 2021 from https:/time.com/ 4793331/instagram-social-media-mental-health/

Mostaghim, R., Etehad, M. (2019). Middle-class Iranians resort to buying rotting produce as U.S. sanctions take a toll. Los Angeles Times. Retrieved July 22, 2020, from https://www.latimes.com/worldnation/story/2019-08-27/iran-trump-sanctions-economy-foodmedicine-shortage.

Motevali, G. (2020). Iran Virus News: Nation Seeks \$5 Billion in IMF Aid. Bloomberg. Retrieved July 21, 2020, from https://bit.ly/ 2BmSdZP.

Nahavandi, M., Moghadam, M. (2018). Barresie tatbishiye avamele moaser bar farhange kar dar Iran va chahar keshvare Asyayi. Faslnameye Oloome Ejtemaei, 27(1), 171-209.

Notash, M., Ghaffari, G., Kazemipour, S., \& Torkaman, F. (2018). Savade ejtemaei va masrafe maddi dar beyne javanane daraye barkhordarye eghtesadi dar Tehran. Motale'ate Jame'e Shenakhtie Shahri, 29, 107-137).

Oskuie, S. M., Mohamadkhani, K., Delavar, A., \& Farhangi, A. A. (2020). Cybercultural Transgressions in Comments by Iranian Instagram Users, Asiascape: Digital Asia, 7(3), 155-186. doi: https://doi.org/10.1163/22142312-12340124

Partain, L. P. B. (2020). Best of both worlds or refusal to comply? The rich kids of Tehran on Instagram. Journal of International and Intercultural Communication, 13, 3, 216-237.

Potter, J. W. (2019). Media literacy ( $9^{\text {th }}$ edition). New York: Sage Publications.

Raha, E. (2019). Cheghadr khoobim ma. Tehran: Morvarid.

Rahmani, T. (2021). Life on the ground in Iran: From the view of the people. Retrieved June 29, 2021 from https://www.wilsoncenter. org/article/life-ground-iran-view-people

Ranjbar, M. (2014). 2.5 million shoghl bedoone motaghazi dar keshvar. Retrieved June 30, 2021 from https://bit.ly/36hZDJX

Ranjbar, M. (2019). Rotbeye sevome masrafe energy va panjome kharide tala be name mast!. Retrieved June 28, 2021 from https://bit.ly/ $2 \mathrm{~T} 7 \mathrm{ftnL}$

Ronen, G. (2011). Iranians ‘Among World's Laziest.' Retrieved June 30, 2021 from https://www.israelnationalnews.com/News/News.aspx/ 147103. 
Sabbar, S., \& Hyun, D. (2016). What do we trust? a study on credibility of new and old media and relations with medium, content and audience characteristics. New Media Studies, 1(4). 205-245.

Sabbar, S., \& Matheson, D. (2019). Mass media vs. the mass of media: a study on the human nodes in a social network and their chosen messages. Journal of Cyberspace Studies, 3(1), 23-42.

Shafaf (2015). Amarhaye ajib as masrafgarayie Iranian. Retrieved June 28, 2021 from https://bit.ly/3x9cWYY

Shahghasemi, E. (2017). Iranians in the Minds of Americans. New York: Nova Publishing.

Shahghasemi, E. (2020a). Iranian Celebrities on the Internet. Journal of Cyberspace Studies, 4(1), 77-80. doi: https://doi.org/10.22059/jcss. 2020.74782

Shahghasemi, E. (2020b). Pornography of Poverty: Celebrities' Sexual Appeal at Service to the Poor?. The 2nd International Conference on Future of Social Sciences and Humanities, Prague.

Shahghasemi, E., Prosser, M. (2019). The Middle East: Social Media Revolution in Public and Private Communication. International Conference on Future of Social Sciences and Humanities, Warsaw.

Shahghasemi, E., Tafazzoli, B. (2013). Scrabble the Face of Your Opponent: Iranian Blogger's Endeavour to Discursively Undermine Ahmadi Nejad's legitimacy. Online International Journal of Arts and Humanities, 2(8), 198-207.

Sinaiee, M. (2021). Inequality rose from 2014 To 2019, Reports Iran's Statistical Center. Retrieved June 28, 2021 from https:/iranintl.com/ en/iran-economy/inequality-rose-2014-2019-reports-iran'sstatistical-center

Soori, A. (2009). Masraf-garayi va eslahe olgooye masraf dar sokhanane rahbare moazami enghelabe Eslami. Golbarge Javan, 111.

Spieler, S. (2015). "Our everyday is better than your best day": Spectacle and politics of ambiguity on the Tumblr blog Rich Kids of Instagram. In S. Herrmann, C. Hoffmann, K. Kanzler, S. Schubert,
\& F. Usbeck (Eds.), Poetics of politics: Textuality and social relevance in contemporary American literature and culture (pp. 291312). Heidelberg: Universitätsverlag.

The World Bank (2020). Iran's Economic Update - April 2020. Retrieved June 28, 2021 from https://www.worldbank.org/en/ country/iran/publication/economic-update-april-2020.

The World Bank (2021a). Iran's Economic Update - April 2021. Retrieved June 28, 2021 from https://www.worldbank.org/en/ country/iran/publication/economic-update-april-2021

The World Bank (2021b). Islamic Republic of Iran. Retrieved June 28, 2021 from https://www.worldbank.org/en/country/iran/overview\#1

Veblen, T. (1899). The Theory of the Leisure Class. New York: MacMillan.

Ward, P. (2012). Gods Behaving Badly: Media, Religion, and Celebrity Culture. Baylor University Press: Waco, Texas.

Williams, O. A. (2021). Iran sees millionaire boom amid sanctions, covid-19 and an election. Retrieved June 30, 2021 from https://bit. $1 y / 3 \times 18 N 3 S$

Publisher's Note Springer Nature remains neutral with regard to jurisdictional claims in published maps and institutional affiliations.

Ehsan Shahghasemi is an assistant professor of communication in the Department of Communication at the University of Tehran. His main interests are intercultural communication, cyberspace studies, and media philosophy. His research projects on intercultural communication are mainly focused on the views which Iranian and American people have of each other. He is also a translator and has translated over 40 books into Persian. 